\title{
Genomic basis of symbiovar mimosae in Rhizobium etli
}

\author{
Marco A Rogel ', Patricia Bustos², Rosa I Santamaría², Víctor González², David Romero ${ }^{2}$, Miguel Ángel Cevallos², \\ Luis Lozano², Jaime Castro-Mondragón' ${ }^{1}$ Julio Martínez-Romero ${ }^{1}$, Ernesto Ormeño-Orrillo ${ }^{1}$ \\ and Esperanza Martínez-Romero ${ }^{\text {* }}$
}

\begin{abstract}
Background: Symbiosis genes (nod and nif) involved in nodulation and nitrogen fixation in legumes are plasmid-borne in Rhizobium. Rhizobial symbiotic variants (symbiovars) with distinct host specificity would depend on the type of symbiosis plasmid. In Rhizobium etli or in Rhizobium phaseoli, symbiovar phaseoli strains have the capacity to form nodules in Phaseolus vulgaris while symbiovar mimosae confers a broad host range including different mimosa trees.

Results: We report on the genome of $R$. etli symbiovar mimosae strain Mim1 and its comparison to that from R. etli symbiovar phaseoli strain CFN42. Differences were found in plasmids especially in the symbiosis plasmid, not only in nod gene sequences but in nod gene content. Differences in Nod factors deduced from the presence of nod genes, in secretion systems or ACC-deaminase could help explain the distinct host specificity. Genes involved in P. vulgaris exudate uptake were not found in symbiovar mimosae but hup genes (involved in hydrogen uptake) were found. Plasmid pRetCFN42a was partially contained in Mim1 and a plasmid (pRetMim1c) was found only in Mim1. Chromids were well conserved.

Conclusions: The genomic differences between the two symbiovars, mimosae and phaseoli may explain different host specificity. With the genomic analysis presented, the term symbiovar is validated. Furthermore, our data support that the generalist symbiovar mimosae may be older than the specialist symbiovar phaseoli.
\end{abstract}

Keywords: Legume nodulation, Bacterial symbiosis, Nitrogen fixation, Host specificity

\section{Background}

Bacterial nitrogen fixation in legume nodules contributes to plant nutrition and allows plants to grow in nitrogen deficient soils. Genes for plant nodulation and nitrogen fixation are plasmid-borne in Rhizobium spp. (reviewed in [1]) and symbiovars define host specificity. There are over twenty different symbiovars reported not only in Rhizobium but also in Bradyrhizobium and in other genera of nodule forming bacteria [2-7]. The term symbiovar was proposed as a counterpart to the term pathovar in pathogenic bacteria [2]. A theoretical model proposes that a single species may exhibit alternative symbiovars depending on the presence of symbiotic plasmids or symbiotic islands [2]. The same symbiovar may be present in

\footnotetext{
* Correspondence: esperanzaeriksson@yahoo.com.mx

${ }^{1}$ Ecological Genomics programs, Genomics Science Center, CCG, Cuernavaca, Morelos, Mexico

Full list of author information is available at the end of the article
}

distinct species as a consequence of the lateral transfer of symbiotic plasmids or islands. Symbiotic genes and other genes associated with niche adaptation may have evolutionary histories independent of the evolution of the chromosomal genes [8]. Two symbiovars are recognized in Rhizobium etli: phaseoli (conferring the ability to nodulate Phaseolus vulgaris) and mimosae (involved in nodulating mimosas and $P$. vulgaris, [9]). Symbiovar mimosae strains were isolated from Mimosa affinis in Morelos and have a broad host range, including plants of M. affinis, Leucaena leucocephala, Calliandra grandiflora, Acaciella angustissima as well as P. vulgaris [9]. Symbiovar mimosae was originally distinguished from sv. phaseoli by the sequence of a few symbiotic genes and by the organization of nif and common nod genes. Multiple copies of nifH genes and a nodA gene separated from $\operatorname{nod} B C$ found in sv. phaseoli and not in sv. mimosae served as a molecular basis to distinguish these

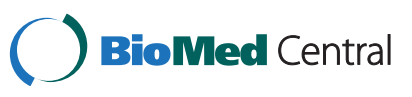


symbiovars $[10,11]$. Phylogenies indicated that symbiovar mimosae and phaseoli nifH genes were related [9] and similar to the corresponding gene in sv. gallicum [12]. Different origins of replication were found in sv. phaseoli and sv. mimosae symbiotic plasmids and both symbiotic plasmids were compatible [9]. It has been proposed that sv. mimosae is older than sv. phaseoli and that the phaseoli symbiotic plasmid was selected by P. vulgaris [13]. P. vulgaris is a recent species (probably two million years old [14]), while mimosas seem to be older.

Mimosas are distributed worldwide with Brazil and Mexico as main diversification sites. Mimosas in South America are nodulated by $\beta$-Proteobacteria like Burkholderia or other $\beta$-Proteobacteria [15-19] while mimosas in Mexico are only exceptionally nodulated by Burkholderia (unpublished). Mimosas from Mexico and Brazil are phylogentically separated [20]. Additionally abiotic conditions like $\mathrm{pH}$ and soil nitrogen content may account for their differences in symbionts [21]. Native mimosas in India are nodulated by sinorhizobia [22], that we have also found in some mimosa nodules in Mexico (unpublished).

Based on multilocus enzyme electrophoresis analysis, $M$. affinis isolate Mim1 was found to group closely to $R$. etli sv. phaseoli CFN 42 [9]. Other M. affinis isolates such as Mim2 were separated from CFN42 (Figure two in [9]) and thus Mim2 has been recently reassigned to Rhizobium phaseoli $[1,23]$. Therefore we recognize now that symbiovar mimosae exists in $R$. phaseoli as well as in $R$. etli. It is the aim of this work to define the genomic differences between two $R$. etli strains (CFN42 and Mim1) representing the symbiovars phaseoli and mimosa, respectively.

\section{Methods}

\section{Strains and growth conditions}

Rhizobium strains were grown overnight at $28^{\circ} \mathrm{C}$ in PY medium [24] after recovery from glycerol stocks at $-80^{\circ} \mathrm{C}$. Bacterial strains to be inoculated on plants were grown on solid PY media and resuspended in water to an $\mathrm{OD}_{600}$ of 0.5 . For PCR or DNA isolation, bacteria were grown in liquid PY cultures [24].

\section{Plasmid profiles}

Plasmid profiles were visualized on agarose gels according to the protocol described by Hynes and McGregor [25]. Plasmid patterns from $R$. etli CFN42 or $R$. leucaenae CFN299 were used as references.

\section{Plant nodulation assays}

L. leucocephala seeds were treated with concentrated sulfuric acid for $15 \mathrm{~min}$, rinsed with water and surface disinfected with sodium hypochlorite as described [26]; the same procedure was used to disinfect $P$. vulgaris seeds. Seeds were germinated in water-agar plates in the dark and transferred to flasks after 3 days. L. leucocephala plants were grown in vermiculite flasks with $\mathrm{N}$ free Fahraeus nutrient solution for 40 days and P. vulgaris plants in agar flasks with the same nutrient solution for 14 days.

\section{Genome sequencing, assembly and annotation}

Genomic DNA from $R$. etli Mim1 was sheared to produce two paired-end libraries for 454 pyrosequencing, one with $3 \mathrm{~Kb}$ inserts and the other with $8 \mathrm{~Kb}$ inserts. An additional $3 \mathrm{~Kb}$ library was sequenced only at one end. The total amount of reads were 512,236 paired reads and 112, 079 single reads. Library construction and sequencing was done at Mogene LC (St. Louis, MO, USA). Additionally two paired-end libraries were constructed, one with $200 \mathrm{bp}$ inserts and the second with 2 $\mathrm{Kb}$ inserts. Both libraries were sequenced by Illumina at BGI (Beijing, China). A total amount of 16, 000, 000 short-paired readings (50-60 bases) were assembled. To improve the scaffolding a BAC library was constructed in pIndogo BAC- $5^{\text {Tw }}$ vector by BIOS\&T (Quebec, Canada) using fragments from a partial genomic DNA HindIII digestion. 105 BAC-ends were sequenced with ABI3730xl sequencer by Sanger method. Additionally, three BACs were completely sequenced with the same technology at the Center for Genomic Sciences (Cuernavaca, México). Two of these BACs were selected by hybridizing with nifH and other pSym probes; they embraced half of the pSym plasmid sequence. The third BAC was from the chromosome. Final assembly of the symbiotic plasmid was obtained using sequence reads from the three sources of information: BAC sequences, Illumina, and 454 pyrosequencing.

Different assembly strategies were used with the following programs: Newbler 2.5.3 (ROCHE), Velvet 1.1.06 [27], Sspace-Basic 2.0 [28], and Consed v23 [29]. ORFs were predicted with Glimmer 3 [30], and annotations were done in Artemis 12.0 graphic display [31] using previous annotations made for R. etli CFN42 [32] and comparing with the non-redundant data base of the Genbank [33], Interpro database [34], and IS database (http://www-is. biotoul.fr).

\section{Sequence analysis}

Average nucleotide identity (ANI) was calculated using the JSpecies software [35]. The DNA conservation between two genomes or replicons was estimated by obtaining an alignment with NUCmer [36], run with default parameters, and dividing the summed lengths of all aligned regions by the length of the genome or replicon and expressing the value obtained as a percentage. Common and specific protein families between $R$. etli CFN42 and Mim1 were detected using MCL as described [37]. 


\section{Genomic islands}

Alien Hunter v1.7 software [38] was used to analyze the chromosome sequence of $R$. etli sv. mimosae Mim1 and $R$. etli CFN42. The minimum region length for HT detection was $5 \mathrm{kbs}$. The score thresholds were 12.92 and 14.96 for Mim1 and CFN42, respectively.

\section{Phylogenetic analysis}

Alignments were performed with MUSCLE [39] and manually verified. Maximum likelihood trees were generated with PhyML [40] with tree node support evaluated by bootstrap analysis based on 1000 pseudoreplicate datasets. Phylogenetic relationships were also assessed by Bayesian inference using MrBayes 3.1 [41]. Analyses were initiated with random starting trees, run for 2,000,000 generations and three separate analyses were executed. Markov chains were sampled every 100 generations. We discarded $25 \%$ of trees as "burn in".

\section{Genome accession numbers}

Sequences and annotations were deposited in the Genbank database under accession numbers CP005950 (chromosome), CP005951 (pRetMim1a), CP005952 (pRetMim1b), CP005953 (pRetMim1c), CP005954 (pRetMim1d), CP005955 (pRetMim1e) and CP005956 (pRetMim1f).

\section{Results and discussion}

\section{Genome of $R$. etli symbiovar mimosae strain Mim1}

The final assembly of the $R$. etli sv. mimosae Mim1 genome rendered seven circular molecules: one chromosome and six plasmids at $150 \times$ coverage on average. The chromosome was $4.8 \mathrm{Mb}$ in size while the plasmids ranged in size from $181 \mathrm{~kb}$ to $1.08 \mathrm{Mb}$ (Figure 1). Average Nucleotide
Identity (ANI) and the percentage of conserved DNA between Mim1 and CFN42 were $98.6 \%$ and $82.4 \%$ respectively on a whole genome analysis, confirming that both strains belong to the same species. Lower ANI (less than 90\%) was found between Mim1 and strains of other species such as $R$. phaseoli and $R$. leguminosarum.

There were more than twice as many unique genes in Mim1 than in CFN42, mainly in plasmids. The respective chromosomes of each strain had around 260 unique genes. In chromosomes, 35 genomic islands were identified only in Mim1 and 17 only in CFN42. (Figure 2); genes found in Mim1 genomic islands are shown in Additional file 1: Table S1. Examples of unique genes found in Mim1 and not in CFN42 are those encoding cytochrome oxidases, some chaperonins, dipeptide transporters, lactate dehydrogenase, a PHB depolymerase, a ferritin-like protein, exopolysaccharide biosynthesis genes, a type VI secretion system and menaquinone biosynthesis as well as many hypothetical genes.

The conserved genome in $R$. etli strains Mim1 and CFN42 includes not only the chromosome but two extrachromosomal replicons (pRetMim1a-pRetCFN42b and pRetMim1d-pRetCFN42e) that have been designated as chromids in CFN42 [42] and one plasmid (pRetMim1b-pRetCFN42c) (Figure 3). Each of the chromids had less than 20 unique genes and the chromid pairs had an ANI around 99\% (Table 1). The small replicons pReCFN42a and pRetMim1c were partially conserved and large genomic differences were found in the symbiotic plasmids (Figures 1 and 4, Table 1).

Mim1 and CFN42 chromosomes were syntenic, as were the chromid pairs pRetMim1a-pRetCFN42b and pRetMim1dpRetCFN42e, and plasmids pRetMim1b-pRetCFN42c. In comparison to $R$. leguminosarum 3841, Mim1 plasmid

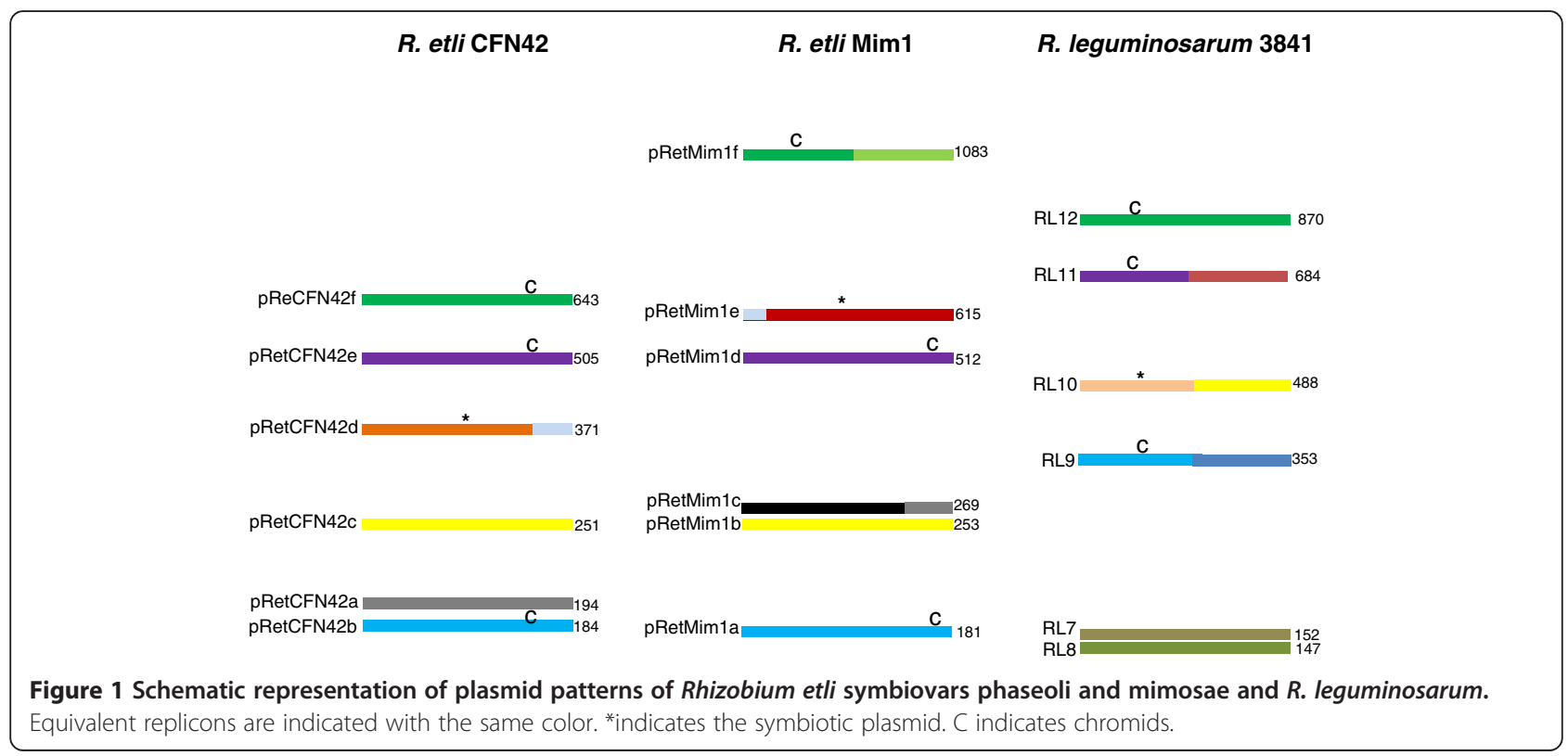




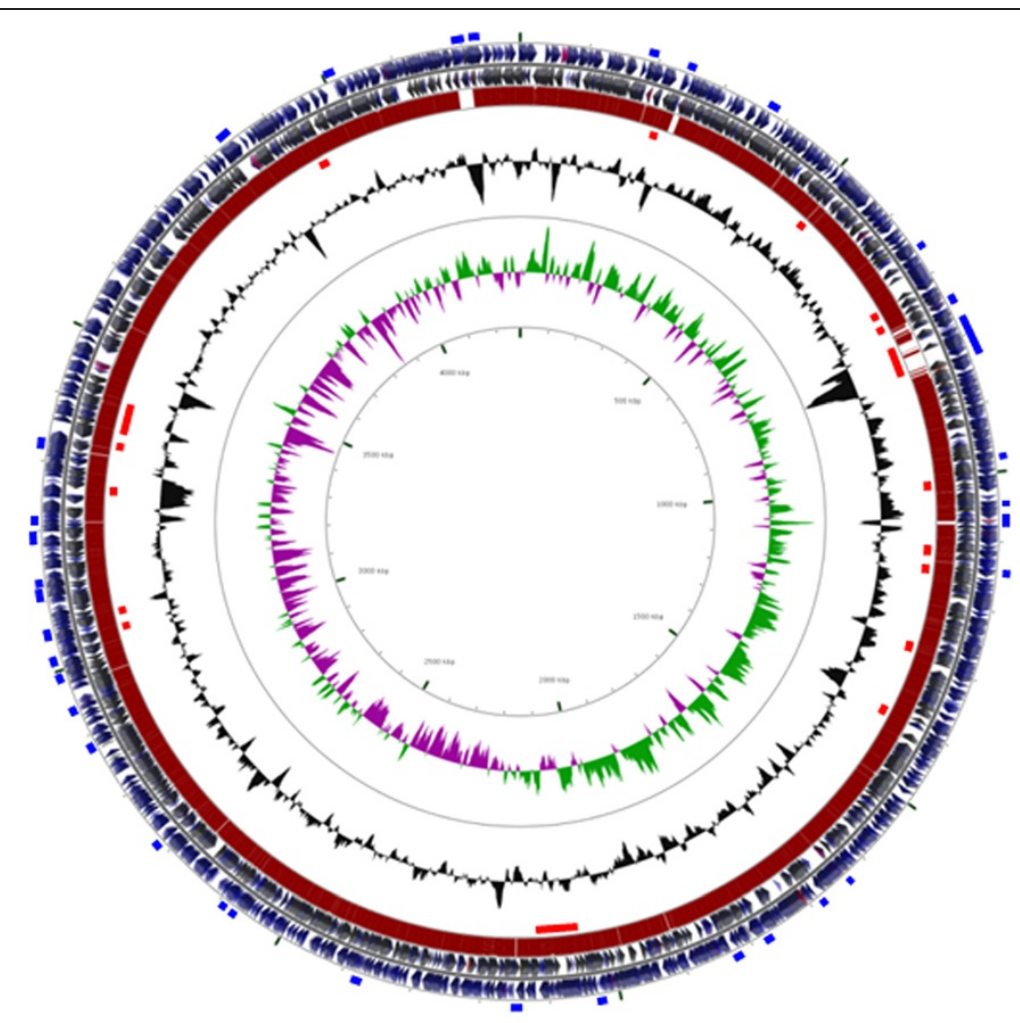

Figure 2 Representation of $\boldsymbol{R}$. etli Mim1 chromosome. Circles from outermost to innermost indicate: genomic islands of Mim1 (in blue), ORFs in the leading strand, ORFs in the lagging strand, BLAST matches against CFN42 chromosome, genomic islands of CFN42 (in red), GC content, GC skew, coordinates.

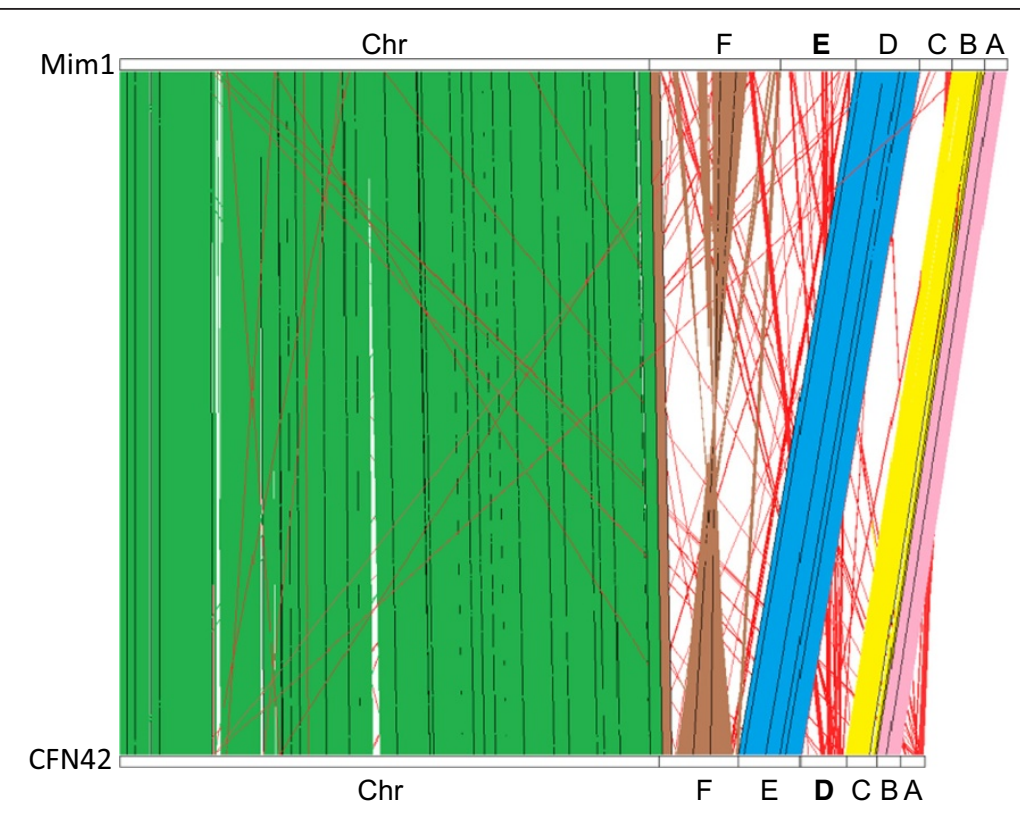

Figure 3 Graphic comparison of equivalences among the $R$. etli CFN42 and $R$. etli Mim 1 genomes. Letters indicate the different extrachromosomal replicons found in both strains (see text). Letters in bold indicate the symbiotic plasmids. 
Table 1 Average nucleotide identity (ANI) and conservation in percent between $R$. etli sv. mimosae Mim1 and $R$. etli sv. phaseoli CFN 42 or R. leguminosarum 3841 replicons

\begin{tabular}{|c|c|c|}
\hline \multirow[t]{2}{*}{ Mim1 replicons } & \multicolumn{2}{|c|}{$\mathrm{ANI}^{*} /$ conservation ${ }^{\S}$ to the corresponding replicons in } \\
\hline & R. etli CFN42 & R. leguminosarum 3841 \\
\hline pRetMim1f & 97.4/51.1 (pReCFN42f) & 86.8/31.4 (pRL12) \\
\hline pRetMim1e (pSym) & 89.2/8.8 (ReCFN42d) & \\
\hline pRetMim1d & 98.9/97.5 (pReCFN42e) & 88.2/61.2 (pRL11) \\
\hline pRetMim1c & 86.4/11.4 (pReCFN42a) & \\
\hline pRetMim1b & 99.1/92.5 (pReCFN42c) & 87.2/55.7 (pRL10) \\
\hline pRetMim1a & 99.2/99.9 (pReCFN42b) & 87.6/58.4 (pRL9) \\
\hline RetMim1Ch & 99.2/97.8 (ReCFN42Ch) & 88.1/78.1 (RLChr) \\
\hline
\end{tabular}

*Average nucleotide identity was calculated using all portions of the replicons that could be aligned with the nucmer program. These regions included both genic and intergenic regions.

${ }^{\S}$ Percentage of the Mim1 replicon involved in the ANI calculation is expressed here as the conservation value.

equivalences were similar to those reported previously for $R$. etli CFN42 [8]. ANI values were lower with $R$. leguminosarum 3841 that among the $R$. etli strains (Table 1).

All extrachromosomal replicons in Mim1 belong to the rep $A B C$ plasmid family [43]. The protein products of the rep $A B C$ operons of the replicon homologous pairs (pRetMim1a-pRetCFN42b, pRetMim1d-pRetCFN42e and pRetMim1b-pRetCFN42c) were almost identical with a sequence identity greater than $97.51 \%$, strongly suggesting that members of each replicon pair belong to the same incompatibility group.

\section{pRetCFN42f-pRetMim1f comparison}

The largest extrachromosomal replicon in Mim1 (pRetMim1f) was only partially conserved in the putative chromid pRetCFN42f (Figures 1 and 4). pRetMim1f and pRetCFN42f possess two rep $A B C$ operons: rep $A B C 1$ and $\operatorname{rep} A B C 2$. The sequence identity between the two rep $A B C$ operons in Mim1 is low. The degree of sequence identities between the corresponding $\operatorname{rep} A B C$ genes of pRetCFN42f and pRetMim1f is large enough to suggest that both plasmids share the same incompatibility group and evolutionary origin. However only $51 \%$ of the pRetMim $1 f$ replicon
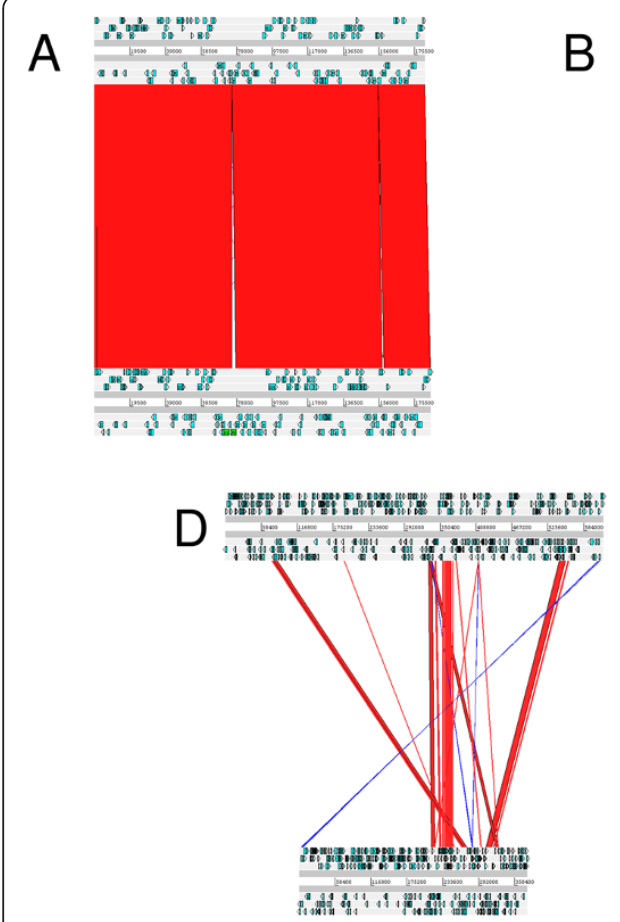

\section{$\mathrm{B}$}

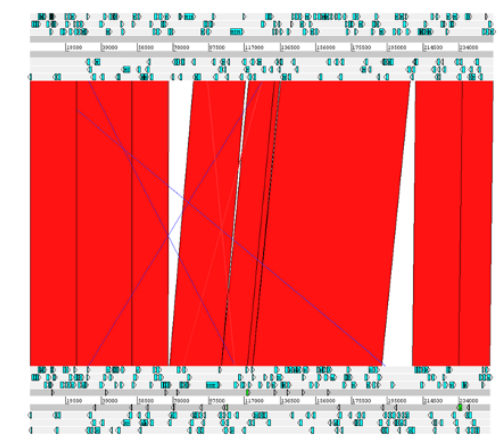

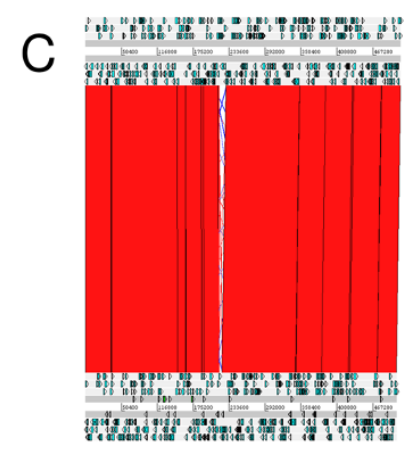

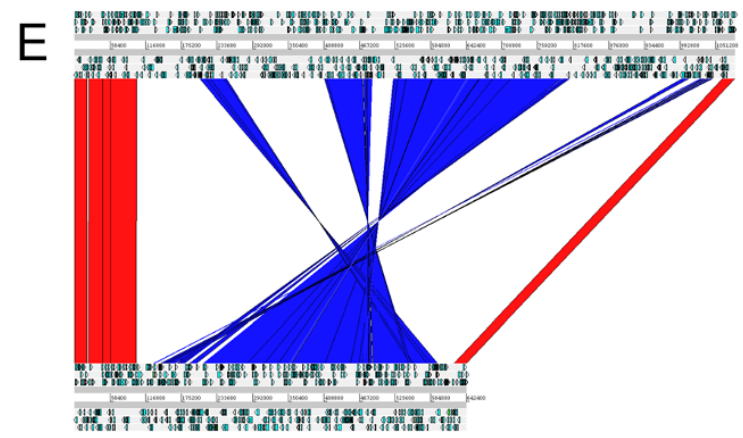

Figure 4 Graphic representation of the alignments of CFN42 (top)-Mim1 (bottom) replicons. A) pRetMim1a-pRetCFN42b, B) pRetMim1bpRetCFN42c, C) pRetMim1d-pRetCFN42e, D) pRetMim1e-pRetCFN42d, E) pRetMim1f-pRetCFN42f. ORFs of each replicon are depicted with light blue arrows in their corresponding reading frame. Syntenic segments oriented in the same or opposite direction are joined by red and blue regions, respectively. 
is conserved in CFN42 while $86 \%$ of pRetCFN42f was found in pRetMim1f (Figures 1 and 4).

Type VI secretion system genes were only found in the megaplasmid pRetMim1f and the conserved impB component is phylogenetically related to the corresponding genes in Rhizobium sp. KIM5 (corresponding to PEL1 lineage, [44]) and R. leguminosarum strain 3841. Mim1 pRetMim1f has a duplicated citrate synthase gene as in sv. tropici symbiotic plasmids. The plasmid duplicated citrate synthase gene in sv. tropici is required for eliciting a normal number of nodules and is regulated differently than the copy in the chromosome [45,46]. A plasmid borne citrate synthase was not found in CFN42. Phylogenetic analysis of citrate synthase genes showed that the Mim1 chromosomal gene product is identical to that of CFN42, while the gene in pRetMim1f has a novel sequence only distantly related to a plasmid copy of $R$. gallicum R602 (55\% identity).

Genes such as rail and raiR were found in the conserved region of pRetCFN42f and pRetMim1f. Rail produces homoserine lactones and RaiR is the transcriptional regulator. The rai system in R. phaseoli sv. phaseoli CNPAF 512 affects nodule number but not nitrogen fixation in $P$. vulgaris [47]. This system also controls growth in $R$. phaseoli [48] and if this is the case in R. etli, this would explain its conservation in both symbiovars.

A transcriptomic study compared the genome expression of $R$. phaseoli Ch24-10 in maize and P. vulgaris rhizospheres [49]. Over 50\% of the extrachromosomal genes highly expressed in $P$. vulgaris but not in maize roots were found in a Ch24-10 replicon equivalent to pRetCFN42f. It seems that genes in this replicon are involved in plant specific interactions.

\section{Symbiosis plasmid gene comparison}

Large differences were observed between the symbiotic plasmids of CFN42 and Mim1 (Figure 4). Around 10\% and $15 \%$ of the symbiotic plasmids of Mim1 and CFN42 had conserved syntenic regions with an average nucleotide identity of $89.2 \%$ (Table 1).

Differences in symbiosis genes in CFN42 and Mim1 genomes are shown in Table 2. The Nod factor from $R$. etli sv. phaseoli strain CFN42 is a pentamer of $\mathrm{N}$-acetylglucosamine with an acetyl fucose at the reducing end and methyl and carbamoyl groups at the non reducing end [50]. The heterologous expression in Azorhizobium caulinodans of Nod modification genes showed that fucosylated Nod factors were the most suitable to induce $P$. vulgaris nodulation [51]. In symbiovar mimosae no genes related to Nod factor fucosylation (nodZ) were observed (Table 2), in their place, nodHPQ genes that modify the Nod factor with sulfate, were found. Such genes are present in sv. tropici strains that are also Leucaena symbionts [10]. Like $R$. etli strain CFN42, Mim1 may produce nodulation factors bearing carbamoyl groups at their non reducing end residues but the position of these
Table 2 Relevant symbiotic plasmid differences between R. etli sv. mimosae Mim1 and $R$. etli sv. phaseoli CFN 42

\begin{tabular}{lcc}
\hline Gene* & \multicolumn{2}{c}{ symbiovar } \\
\cline { 2 - 3 } & mimosae & phaseoli \\
\hline nodHPQ & + & - \\
nodZ & - & + \\
noll & - & + \\
nodO & + & - \\
nolO & - & + \\
nodU & + & - \\
fixKL & + & - \\
fxkR & + & - \\
acdS & + & - \\
teu & - & + \\
hup-hyp & + & - \\
\hline
\end{tabular}

*Functions of each gene are explained in the text.

decorations must differ because their pSyms encoded distinct carbamoyl transferases, NolO in CFN42 and NodU in Mim1. Carbamoylation at the C-6 position introduced by NodU maybe promotes Leucaena nodulation [52,53]. Both Mim1 and CFN42 symbiotic plasmids carry nodS involved in methylation at the non reducing end, a decoration that is essential for bean and Leucaena nodulation in $R$. tropici CIAT 899 [52]. A nodO homologue, 70\% identical to that of Rhizobium sp. BR816, was found only in the sv. mimosae pSym. It has been shown that heterologous expression of nodO can improve nodulation of $L$. leucocephala by different rhizobia and can even extend the host range [54,55].

Mim1 nod gene phylogenies are congruent, resembling the corresponding genes from sv. giardinii (not shown) while Mim1 nifH genes resemble those from sv. phaseoli. Different NodDs in phaseoli and mimosae symbiovars may reflect their affinities for the different flavonoids exuded by the different host plants. Mim1 nodH gene (encoding the sulfotransferase involved in the synthesis of the Nod factor) resembles the corresponding gene in Rhizobium sp. IE4771 that represents a novel genomic lineage related to $R$. etli and $R$. phaseoli $[1,44]$.

acdS gene coding ACC-deaminase was found in the symbiotic plasmid of Mim1 but not in CFN42. ACC-deaminase decreases the amount of ACC that is a precursor of ethylene that may diminish nodule number. A heterologous ACCdeaminase in Rhizobium sp TAL 1145 enhanced nodulation in Leucaena [56].

In CFN42, the fixGHIS-fixNOQP genes required for biosynthesis of the symbiotic terminal oxidase are present in the pSym and also in pRetCFN42f [57]. The regulatory genes fixK and fixL are adjacent to this reiteration in pRetCFN42f while a fixK pseudogene is found in the pSym [58]. In Mim1, we found that the symbiotic terminal oxidase genes are also reiterated in pRetMim1f but, in contrast to 
CFN42, the sv mimosae pSym carried complete fixK and fixL genes. The fixGHIS-fixNOQP-fixKL region shared by pSym and pRetMim1f plasmids in Mim1 is $95 \%$ identical while the reiterated regions in CFN42 are only $87 \%$ identical. The recently described $f x k R$ gene in pRetCFN42f [59], coding for a response regulator that acts in conjunction with FixL and FixK, is present in the sv. mimosae pSym. There is a reiteration of this gene in pRetMim1f as well.

Genes involved in P. vulgaris exudate uptake (teu genes, [60]) are found in the symbiotic plasmids in symbiovar phaseoli strains $R$. etli CFN42 and $R$, phaseoli CIAT652 but they were not found in the Mim1 genome. Rhizobium mutants in teu genes had reduced nodulation competitiveness in $P$. vulgaris [60].

The symbiosis plasmid of Mim1 has genes for a type III secretion system (T3SS) that are more closely related to those found in Mesorhizobium and Sinorhizobium strains than to those encoded in the CFN42 pSym (not shown). This difference may contribute to the disparate host ranges displayed by Sv. phaseoli and mimosae strains considering the function of rhizobial T3SS in specificity [61].

A cluster of hup-hyp genes encoding the components of an uptake hydrogenase (Hup) was found in the pSym of Mim1 but not in CFN42. The Mim1 products showed high identities $(>70 \%)$ to their counterparts coded in $R$. leguminosarum and $R$. tropici [10,62]. $R$. tropici CIAT 899 lacks several hup genes and displays a Hup minus phenotype. In Mim1, all genes except hupE are present. HupE is an uptake transporter for nickel [63], a metal required for Hup function. Since another nickel transporter is encoded elsewhere in Mim1 symbiotic plasmid, the Hup system could be functional.

Mim1 symbiotic plasmid has a $\operatorname{rep} A B C$ origin of replication as well as a repC gene that are not phylogenetically related to the $R$. etli CFN42 corresponding genes. pRetMim1e repC resembles those from $R$. gallicum and Rhizobium sp. Sv. giardinii IE4771 (corresponding to PEL1 lineage). Mim1 $\operatorname{rep} A B C$ from the pSym resembles the corresponding genes in $R$. endophyticum CCGE502 but an extensive plasmid conservation was not observed. CCGE502 is $\mathrm{Nod}^{-}$and does not have a symbiotic plasmid [64].

The analysis of insertion sequences in R. etli CFN42 suggested that the symbiotic plasmid did not significantly share IS sequences with the rest of the genome [65]. This was interpreted as evidence that the pSym was a recent acquisition in this bacterium. The analysis of IS sequences in Mim1 indicated that the symbiotic plasmid had the largest number of IS sequences, some of them shared with the chromosome, pRetMim1f and pRetMim1b, this may perhaps indicate that this symbiotic plasmid has an older history with the $R$. etli genomic background than the phaseoli plasmid. Mim1 has a large number of IS66 that are common in rhizobia.

Genome similarities were found among the different Mim1 replicons. pRetMim1e (pSym) has similar sequences to pRetMim1c and the same is observed among pRetMim1e
(pSym) and pRetMim1f (Figure 5). The similarities of Mim1 symbiotic plasmid and the putative chromid pRetMim1f could support that symbiovar mimosae symbiotic plasmid is ancestral in $R$. etli. In contrast the phaseoli symbiotic plasmid was found dissimilar to the rest of the genomic background in $R$. etli, except to pReCFN42a [32,66].

In $R$. etli CFN42, the symbiotic plasmid and pRetCFN42a have common sequences such as tra and vir genes and repeated sequences that mediate the natural cointegration of both plasmids for the conjugative transfer of CFN42 pSym [67]. In contrast to pReCFN42a, pRetMim1c from Mim1 does not seem to participate in the transfer of the Mim1 symbiotic plasmid, which we have been unable to transfer to other bacterial hosts (Marco A. Rogel, unpublished observations).

\section{Plant-interaction genes not in the symbiosis plasmid}

Some genes involved in plant interactions were found conserved in both symbiovars, such as those encoding $\mathrm{Rmr}$ extrusion pumps that may be involved in eliminating plant produced phytoalexins. $R$. etli mutants in these genes had reduced nodulation [68]. Those genes are encoded in chromid pRetCFN42b in CFN42 and in the corresponding replicon pRetMim1a. $r m r A$ gene had 97\% identity and $r m r B$ and $r m r R$ genes $98 \%$ in CFN42 and Mim1 genomes. Homologous genes were found being expressed in different plant rhizospheres $[1,49,69]$.

Even though sv. mimosae strains are capable of forming nodules in Leucaena, we did not find genes resembling mid or pyd genes involved in the catabolism of the toxic

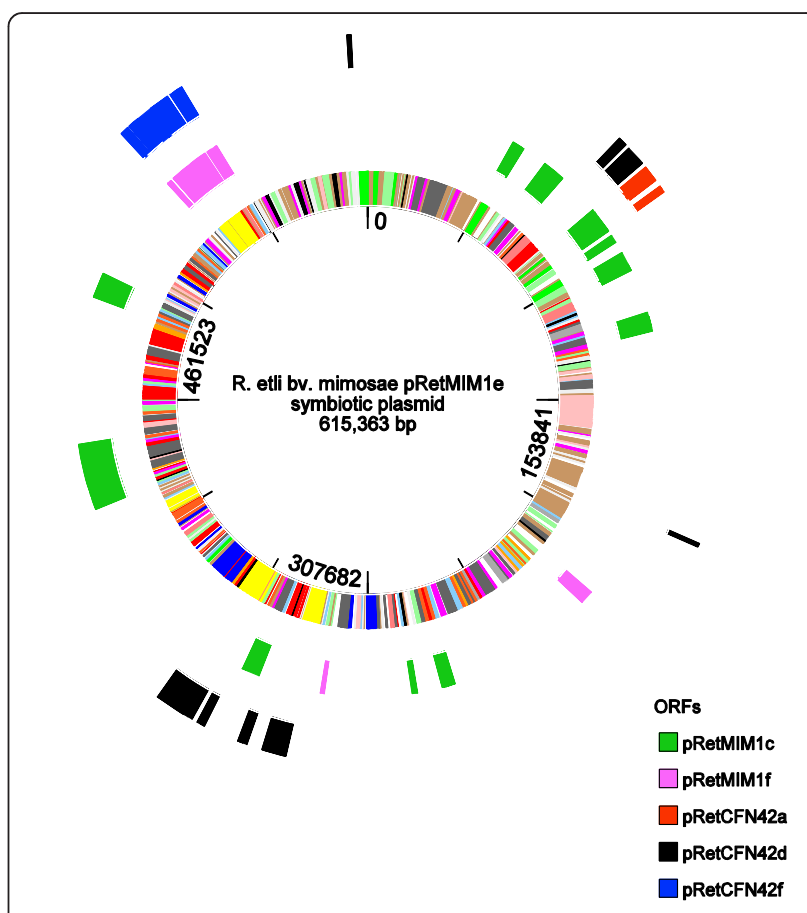

Figure 5 Graphic comparison of the Mim1 symbiotic plasmid pRetMim1e compared to other rhizobial replicons. 
amino acid derivative mimosine found in Leucaena plants. Such genes were described from a Rhizobium sp. strain TAL 1145 (related to $R$. tropici) that was isolated from Leucaena plants [70]. Mimosa pigra has a much lower level of mimosine that Leucaena plants [71] and data for other mimosa species is not available.

\section{Symbiovar phaseoli is prevalent in different Phaseolus vulgaris nodule bacteria}

$R$. etli sv. mimosae strains have a broader host range than symbiovar phaseoli strains. In particular, L. leucocephala plants served as a host to distinguish symbiovar mimosae strains. Thirty-six $P$. vulgaris nodulating bacteria (with $R$. etli-like 16S rRNA gene sequences) obtained from the rain forest of Los Tuxtlas in Mexico corresponded to symbiovar phaseoli on the basis of nodA gene organization [10] and for being unable to nodulate Leucaena plants. We found that some strains that were previously classified as $R$. etli such as CIAT652, Ch24-10, CNPAF512, 8C-3 and Brasil5 now assigned to $R$. phaseoli [1], as well as others like Kim5, GR56 and CIAT 894 now assigned to recently named novel lineages [44] corresponded to sv. phaseoli when we analyzed their genomes. Symbiotic plasmids are highly conserved in symbiovar phaseoli [66] perhaps from being recently evolved [13]. Considering that the majority of $P$. vulgaris nodule isolates tested corresponded to sv. phaseoli we may conclude that this symbiovar is better adapted to its host, thus phaseoli seems to be a specialist symbiovar having a narrow range not including mimosa plants. The phaseoli symbiovar is found in several Rhizobium species or lineages ( $R$. gallicum, R. giardinii, $R$, phaseoli, R. etli and Rhizobium sp. corresponding to PEL1 lineage). The widespread of this symbiovar may be in relation to its host historic worldwide distribution and to the transferability of the symbiotic plasmid, seemingly an epidemic plasmid. Besides having the phaseoli symbiovar, the Rhizobium species mentioned above have additional generalist symbiovars: gallicum or giardinii or mimosae Having alternative symbiovars with different host ranges may be advantageous in rhizobia, as it expands their legume niches and allows them to avoid the specialistgeneralist dilemma.

\section{Conclusions}

The term symbiovar is validated with genomic analyses that show that a common genomic background may harbor different symbiotic plasmids determining host specificity. However, besides differences in the symbiotic plasmids there were differences in other ERs and in the chromosomes in the two strains analyzed, CFN42 and Mim1. In Mim1, Nod factors with sulfate modifications, secretion systems or ACC-deaminase may help explain the extended host range of symbiovar mimosae. In CFN42, teu genes that participate in exudate uptake [60] and genes involved in Nod factor fucosylation (nodZ) may contribute to $P$. vulgaris host specialization. The discussion that mimosae is older than phaseoli may apply to gallicum and giardinii, thus we propose that gallicum and giardinii are older than phaseoli.

\section{Additional file}

Additional file 1: Table S1. Genes found in different genomic islands exclusive of Mim1.

\section{Competing interests}

The authors declare that they have no competing interests.

\section{Authors' contributions}

EMR initiated and designed the study. MAR performed experiments. VG, DR, MAC contributed reagents and analyzed data. EOO, PB, RIS, JMR, JCM, LL performed data analysis. EMR, EOO, MAR wrote the paper. All authors read and approved the manuscript.

\section{Acknowledgements}

To PAPIIT 205412, CONACYT CB 131499 and CONACyT 154453 for financial support. To Michael Dunn for reading the paper. MA Rogel was a Ph.D. student at the Biological Sciences program in UNAM Mexico and supported by a PASPA fellowship.

\section{Author details}

${ }^{1}$ Ecological Genomics programs, Genomics Science Center, CCG, Cuernavaca, Morelos, Mexico. ${ }^{2}$ Evolutionary Genomics programs, Genomics Science Center, CCG, Cuernavaca, Morelos, Mexico. ${ }^{3}$ Genome Engineering programs, Genomics Science Center, CCG, Cuernavaca, Morelos, Mexico.

Received: 2 September 2013 Accepted: 1 July 2014

Published: 8 July 2014

\section{References}

1. López-Guerrero MG, Ormeño-Orrillo E, Velázquez E, Rogel MA, Acosta JL, Gónzalez V, Martínez J, Martínez-Romero E: Rhizobium etli taxonomy revised with novel genomic data and analyses. Syst Appl Microbiol 2012, 35:353-358.

2. Rogel MA, Ormeño-Orrillo E, Martinez Romero E: Symbiovars in rhizobia reflect bacterial adaptation to legumes. Syst App/ Microbio/ 2011, 34:96-104

3. Cobo-Díaz JF, Martínez-Hidalgo P, Fernández-González AJ, Martínez-Molina E, Toro N, Velázquez E, Fernández-López M: The endemic Genista versicolor from Sierra Nevada National Park in Spain is nodulated by putative new Bradyrhizobium species and a novel symbiovar (sierranevadense). Syst Appl Microbiol 2013, 37:177-185.

4. Gubry-Rangin C, Béna G, Cleyet-Marel JC, Brunel B: Definition and evolution of a new symbiovar, sv. rigiduloides, among Ensifer meliloti efficiently nodulating Medicago species. Syst Appl Microbiol 2013, 36:490-496.

5. Ramírez-Bahena $\mathrm{MH}$, Chahboune R, Velázquez E, Gómez-Moriano A, Mora E, Peix A, Toro M: Centrosema is a promiscuous legume nodulated by several new putative species and symbiovars of Bradyrhizobium in various American countries. Syst Appl Microbiol 2013, 36:392-400.

6. Laranjo M, Young JP, Oliveira S: Multilocus sequence analysis reveals multiple symbiovars within Mesorhizobium species. Syst Appl Microbiol 2012, 35:359-367.

7. Ramírez-Bahena MH, Hernández M, Peix A, Velázquez E, León-Barrios M: Mesorhizobial strains nodulating Anagyris latifolia and Lotus berthelotii in Tamadaya ravine (Tenerife, Canary Islands) are two symbiovars of the same species, Mesorhizobium tamadayense sp. nov. Syst Appl Microbiol 2012, 35:334-341.

8. Crossman LC, Castillo-Ramírez S, McAnnula C, Lozano L, Vernikos GS, Acosta JL, Ghazoui ZF, Hernández-González I, Meakin G, Walker AW, Hynes MF, Young JP, Downie JA, Romero D, Johnston AW, Dávila G, Parkhill J, González V: A common genomic framework for a diverse assembly of plasmids in the symbiotic nitrogen fixing bacteria. PLoS One 2008, 3:e2567. 
9. Wang ET, Rogel MA, García-de los Santos A, Martínez-Romero J, Cevallos MA, Martínez-Romero E: Rhizobium etli bv. mimosae, a novel biovar isolated from Mimosa affinis. Int J Syst Bacteriol 1999, 49:1479-1491.

10. Ormeño-Orrillo E, Rogel-Hernández MA, Lloret L, López-López A, Martínez J, Barois I, Martínez-Romero E: Change in land use alters the diversity and composition of Bradyrhizobium communities and led to the introduction of Rhizobium etli into the tropical rain forest of Los Tuxtlas (Mexico). Microb Ecol 2012, 63:822-834.

11. Vázquez M, Dávalos A, de las Peñas A, Sánchez F, Quinto C: Novel organization of the common nodulation genes in Rhizobium leguminosarum bv. phaseoli strains. J Bacteriol 1991, 173:1250-1258.

12. Silva C, Vinuesa P, Eguiarte LE, Souza V, Martínez-Romero E: Evolutionary genetics and biogeographic structure of Rhizobium gallicum sensu lato, a widely distributed bacterial symbiont of diverse legumes. $\mathrm{Mol}$ Ecol 2005, 14:4033-4050.

13. Martínez-Romero E: Coevolution in Rhizobium-legume symbiosis? DNA Cell Biol 2009, 28:361-370.

14. Delgado-Salinas A, Bibler R, Lavin M: Phylogeny of the genus Phaseolus (Leguminosae): a recent diversification in an ancient landscape. Syst Bot 2006, 31:779-791.

15. Dos Reis FBJ, Simon MF, Gross E, Boddey RM, Elliott GN, Neto NE, Loureiro MF, de Queiroz LP, Scotti MR, Chen WM, Norén A, Rubio MC, de Faria SM, Bontemps C, Goi SR, Young JP, Sprent Jl, James EK: Nodulation and nitrogen fixation by Mimosa spp. in the Cerrado and Caatinga biomes of Brazil. New Phytol 2010, 186:934-946.

16. Chen WM, de Faria SM, James EK, Elliott GN, Lin KY, Chou JH, Sheu SY, Cnockaert M, Sprent Jl, Vandamme P: Burkholderia nodosa sp. nov. isolated from root nodules of the woody Brazilian legumes Mimosa bimucronata and Mimosa scabrella. Int J Syst Evol Microbiol 2007, 57:1055-1059.

17. Chen WM, de Faria SM, Chou JH, James EK, Elliott GN, Sprent Jl, Bontemps C, Young JP, Vandamme P: Burkholderia sabiae sp. nov., isolated from root nodules of Mimosa caesalpiniifolia. Int J Syst Evol Microbiol 2008, 58:2174-2179.

18. Sheu SY, Chou JH, Bontemps C, Elliott GN, Gross E, James EK, Sprent J, Young JP, Chen WM: Burkholderia symbiotica sp. nov., isolated from root nodules of Mimosa spp. native to north-east Brazil. Int J Syst Evol Microbiol 2012, 62:2272-2278.

19. Taulé C, Zabaleta M, Mareque C, Platero R, Sanjurjo L, Sicardi M, Frioni L, Battistoni F, Fabiano E: New Betaproteobacterial Rhizobium strains able to efficiently nodulate Parapiptadenia rigida (Benth.) Brenan. Appl Environ Microbiol 2012, 78:1692.

20. Simon MF, Grether R, de Queiroz LP, Särkinen TE, Dutra VF, Hughes CE: The evolutionary history of Mimosa (Leguminosae): toward a phylogeny of the sensitive plants. Am J Bot 2011, 98:1201-1221.

21. Elliott GN, Chou JH, Chen WM, Bloemberg GV, Bontemps C, MartínezRomero E, Velázquez E, Young JP, Sprent Jl, James EK: Burkholderia spp. are the most competitive symbionts of Mimosa, particularly under $\mathrm{N}$-limited conditions. Environ Microbiol 2009, 11:762-778.

22. Gehlot HS, Tak N, Kaushik M, Mitra S, Chen W-M, Poweleit N, Panwar D, Poonar N, Parihar R, Tak A, Sankhla IS, Ojha A, Rao SR, Simon MF, Dos Reis FB, Perigolo N, Tripathi A, Sprent JI, Young JPW, James EK, Gyaneshwar P: An invasive Mimosa in India does not adopt the symbionts of its native relatives. Ann Bot 2013. in press.

23. Robledo $M$, Velázquez E, Ramírez-Bahena MH, García-Fraile P, Pérez-Alonso A, Rivas R, Martínez-Molina E, Mateos PF: The celC gene, a new phylogenetic marker useful for taxonomic studies in Rhizobium. Syst Appl Microbiol 2011, 34:393-399.

24. Toledo I, Lloret L, Martínez-Romero E: Sinorhizobium americanum sp. nov., a new Sinorhizobium species nodulating native Acacia spp. in Mexico. Syst Appl Microbiol 2003, 26:54-64. Erratum in: Syst Appl Microbiol 2003, 26:319.

25. Hynes MF, McGregor NF: Two plasmids other than the nodulation plasmid are necessary for formation of nitrogen-fixing nodules by Rhizobium leguminosarum. Mol Microbiol 1990, 4:567-574.

26. Martinez-Romero E, Rosenblueth M: Increased bean (Phaseolus vulgaris L.) nodulation competitiveness of genetically modified Rhizobium strains. Appl Environ Microbiol 1990, 56:2384-2388.

27. Zerbino DR, Birney E: Velvet: algorithms for de novo short read assembly using de Bruijn graphs. Genome Res 2008, 18:821-829.

28. Boetzer M, Henkel CV, Jansen HJ, Butler D, Pirovano W: Scaffolding pre-assembled contigs using SSPACE. Bioinformatics 2011, 27:578-579.
29. Gordon D, Abajian C, Green P: Consed: a graphical tool for sequence finishing. Genome Res 1998, 8:195-202.

30. Delcher AL, Harmon D, Kasif S, White O, Salzberg SL: Improved microbial gene identification with GLIMMER. Nucleic Acids Res 1999, 27:4636-4641.

31. Rutherford K, Parkhill J, Crook J, Horsnell T, Rice P, Rajandream M-A, Barrell B: Artemis: sequence visualization and annotation. Bioinformatics 2000, 16:944-945

32. González V, Santamaría RI, Bustos P, Hernández-González I, Medrano-Soto A, Moreno-Hagelsieb G, Janga SC, Ramírez MA, Jiménez-Jacinto V, ColladoVides J, Dávila G: The partitioned Rhizobium etli genome: genetic and metabolic redundancy in seven interacting replicons. Proc Natl Acad Sci U S A 2006, 103:3834-3839.

33. Benson DA, Karsch-Mizrachi I, Lipman DJ, Ostell J, Wheeler DL: GenBank. Nucleic Acids Res 2008, 36:D25-D30.

34. Apweiler R, Attwood TK, Bairoch A, Bateman A, Birney E, Biswas M, Bucher P, Cerutti L, Corpet F, Croning MDR, Durbin R, Falquet L, Fleischmann W, Gouzy J, Hermjakob H, Hulo N, Jonassen I, Kahn D, Kanapin A, Karavidopoulou Y, Lopez R, Marx B, Mulder NJ, Oinn TM, Pagni M, Servant F, Sigrist CJA, Zdobnov EM: The InterPro database, an integrated documentation resource for protein families, domains and functional sites. Nucleic Acids Res 2001, 29:37-40.

35. Richter M, Rossello-Mora R: Shifting the genomic gold standard for the prokaryotic species definition. Proc Natl Acad Sci U S A 2009, 106:19126-19131.

36. Kurtz S, Phillippy A, Delcher AL, Smoot M, Shumway M, Antonescu C, Salzberg SL: Versatile and open software for comparing large genomes. Genome Biol 2004, 5:R12.

37. Enright AJ, Van Dongen S, Ouzounis CA: An efficient algorithm for large-scale detection of protein families. Nucleic Acids Res 2002, 30:1575-1584

38. Vernikos GS, Parkhill J: Interpolated variable order motifs for detection of horizontally acquired DNA: revisiting the Salmonella pathogenicity islands. Bioinformatics 2006, 22:2196-2203.

39. Edgar RC: MUSCLE: multiple sequence alignment with high accuracy and high throughput. Nucleic Acids Res 2004, 32:1792-1797.

40. Guindon S, Dufayard J-F, Lefort V, Anisimova M, Hordijk W, Gascuel O: New algorithms and methods to estimate Maximum-Likelihood phylogenies: assessing the performance of PhyML 3.0. Syst Biol 2010, 59:307-321.

41. Ronquist $F$, Huelsenbeck JP: MrBayes 3: Bayesian phylogenetic inference under mixed models. Bioinformatics 2003, 19:1572-1574.

42. Harrison PW, Lower RP, Kim NK, Young JP: Introducing the bacterial 'chromid': not a chromosome, not a plasmid. Trends Microbiol 2010, 18:141-148.

43. Cevallos MA, Cervantes-Rivera R, Gutiérrez-Ríos RM: The repABC plasmid family. Plasmid 2008, 60:19-37.

44. Ribeiro RA, Ormeño-Orrillo E, Fuzinatto Dall'Agnol R, Graham PH, MartínezRomero E, Hungria M: Novel Rhizobium lineages isolated from root nodules of common bean (Phaseolus vulgaris L.) in Andean and Mesoamerican areas. Res Microbiol 2013. in press.

45. Pardo MA, Lagunez J, Miranda J, Martínez E: Nodulating ability of Rhizobium tropici is conditioned by a plasmid-encoded citrate synthase. Mol Microbiol 1994, 11:315-321.

46. Hernández-Lucas I, Pardo MA, Segovia L, Miranda J, Martínez-Romero E: Rhizobium tropici chromosomal citrate synthase gene. Appl Environ Microbiol 1995, 61:3992-3997.

47. Rosemeyer V, Michiels J, Verreth C, Vanderleyden J: Iuxl- and luxRhomologous genes of Rhizobium etli CNPAF512 contribute to synthesis of autoinducer molecules and nodulation of Phaseolus vulgaris. J Bacteriol 1998, 180:815-821.

48. Daniels R, De Vos DE, Desair J, Raedschelders G, Luyten E, Rosemeyer V, Verreth C, Schoeters E, Vanderleyden J, Michiels J: The cin quorum sensing locus of Rhizobium etli CNPAF512 affects growth and symbiotic nitrogen fixation. J Biol Chem 2002, 277:462-468.

49. López-Guerrero MG, Ormeño-Orrillo E, Acosta JL, Mendoza-Vargas A, Rogel MA, Ramírez MA, Rosenblueth M, Martínez-Romero J, Martínez-Romero E: Rhizobial extrachromosomal replicon variability, stability and expression in natural niches. Plasmid 2012,68:149-158.

50. Poupot R, Martinez-Romero E, Gautier N, Promé JC: Wild type Rhizobium etli, a bean symbiont, produces acetyl-fucosylated, N-methylated, and carbamoylated nodulation factors. J Biol Chem 1995, 270:6050-6055.

51. Laeremans T, Snoeck C, Mariën J, Verreth C, Martínez-Romero E, Promé JC, Vanderleyden J: Phaseolus vulgaris recognizes Azorhizobium caulinodans 
Nod factors with a variety of chemical substituents. Mol Plant Microbe Interact 1999, 12:820-824.

52. Waelkens F, Voets T, Vlassak K, Vanderleyden J, van Rhijn P: The nodS gene of Rhizobium tropici strain CIAT899 is necessary for nodulation on Phaseolus vulgaris and on Leucaena leucocephala. Mol Plant Microbe Interact 1995, 8:147-154.

53. Perret $X$, Staehelin C, Broughton WJ: Molecular basis of symbiotic promiscuity. Microbiol Mol Biol Rev 2000, 64:180-201.

54. van Rhijn P, Luyten E, Vlassak K, Vanderleyden J: Isolation and characterization of a pSym locus of Rhizobium sp. BR816 that extends nodulation ability of narrow host range Phaseolus vulgaris symbionts to Leucaena leucocephala. Mol Plant Microbe Interact 1996, 9:74-77.

55. Vlassak KM, Luyten E, Verreth $C$, van Rhijn $P$, Bisseling $T$, Vanderleyden J: The Rhizobium sp. BR816 nodO gene can function as a determinant for nodulation of Leucaena leucocephala, Phaseolus vulgaris, and Trifolium repens by a diversity of Rhizobium spp. Mol Plant Microbe Interact 1998, 11:383-392.

56. Tittabutr P, Awaya JD, Li QX, Borthakur D: The cloned 1aminocyclopropane-1-carboxylate (ACC) deaminase gene from Sinorhizobium sp. strain BL3 in Rhizobium sp. strain TAL1145 promotes nodulation and growth of Leucaena leucocephala. Syst Appl Microbiol 2008, 31:141-150

57. González V, Bustos P, Ramírez-Romero MA, Medrano-Soto A, Salgado H, Hernández-González I, Hernández-Celis JC, Quintero V, Moreno-Hagelsieb G, Girard L, Rodríguez O, Flores M, Cevallos MA, Collado-Vides J, Romero D, Dávila G: The mosaic structure of the symbiotic plasmid of Rhizobium etli CFN42 and its relation to other symbiotic genome compartments. Genome Biol 2003, 4:R36.

58. Girard L, Brom S, Dávalos A, López O, Soberón M, Romero D: Differential regulation of fixN-reiterated genes in Rhizobium etli by a novel fixL-fixK cascade. Mol Plant Microbe Interact 2000, 12:1283-1292.

59. Zamorano-Sánchez D, Reyes-González A, Gómez-Hernández N, Rivera P, Georgellis D, Girard L: FxkR provides the missing link in the fixL-fixK signal transduction cascade in Rhizobium etli CFN42. Mol Plant Microbe Interact 2012, 25:1506-1517.

60. Rosenblueth M, Hynes MF, Martínez-Romero E: Rhizobium tropici teu genes involved in specific uptake of Phaseolus vulgaris bean-exudate compounds. Mol Gen Genet 1998, 258:587-598.

61. Fauvart M, Michiels J: Rhizobial secreted proteins as determinants of host specificity in the rhizobium-legume symbiosis. FEMS Microbiol Lett 2008, 285:1-9.

62. Baginsky C, Brito B, Imperial J, Palacios J-M, Ruiz-Argüeso T: Diversity and evolution of hydrogenase systems in rhizobia. Appl Environ Microbio 2002, 68:4915-4924.

63. Brito B, Prieto RI, Cabrera E, Mandrand-Berthelot MA, Imperial J, Ruiz-Argueso T, Palacios JM: Rhizobium leguminosarum hupE encodes a nickel transporter required for hydrogenase activity. J Bacterio/ 2010, 192:925-935.

64. López-López A, Rogel MA, Ormeño-Orrillo E, Martínez-Romero J, MartínezRomero E: Phaseolus vulgaris seed-borne endophytic community with novel bacterial species such as Rhizobium endophyticum sp. nov. Syst Appl Microbiol 2010, 33:322-327.

65. Lozano L, Hernández-González I, Bustos P, Santamaría Rl, Souza V, Young JP, Dávila G, González V: Evolutionary dynamics of insertion sequences in relation to the evolutionary histories of the chromosome and symbiotic plasmid genes of Rhizobium etli populations. Appl Environ Microbiol 2010, 76:6504-6513.

66. González V, Acosta JL, Santamaría Rl, Bustos P, Fernández JL, Hernández González IL, Díaz R, Flores M, Palacios R, Mora J, Dávila G: Conserved symbiotic plasmid DNA sequences in the multireplicon pangenomic structure of Rhizobium etli. Appl Environ Microbiol 2010, 76:1604-1614.

67. Brom S, Girard L, Tun-Garrido C, García-de los Santos A, Bustos P, González V, Romero D: Transfer of the symbiotic plasmid of Rhizobium etli CFN42 requires cointegration with $\mathrm{p} 42 \mathrm{a}$, which may be mediated by site-specific recombination. J Bacteriol 2004, 186:7538-7548.

68. González-Pasayo R, Martínez-Romero E: Multiresistance genes of Rhizobium etli CFN42. Mol Plant Microbe Interact 2000, 13:572-577.
69. Ramachandran VK, East AK, Karunakaran R, Downie JA, Poole PS: Adaptation of Rhizobium leguminosarum to pea, alfalfa and sugar beet rhizospheres investigated by comparative transcriptomics. Genome Biol 2011, 12:R106.

70. Borthakur D, Soedarjo M: Isolation and Characterization of a DNA Fragment Containing Genes for Mimosine Degradation from Rhizobium sp. Strain TAL1145. In Highlights of Nitrogen Fixation Research. Edited by Martinez E, Hernandez G. New York: Kluwer/Plenum; 1999:91-95.

71. Soedarjo M, Borthakur D: Mimosine, a toxin produced by the tree-legume Leucaena provides a nodulation competition advantage to mimosinedegrading Rhizobium strains. Soil Biol Biochem 1998, 30:1605-1613.

doi:10.1186/1471-2164-15-575

Cite this article as: Rogel et al:: Genomic basis of symbiovar mimosae in Rhizobium etli. BMC Genomics 2014 15:575.

\section{Submit your next manuscript to BioMed Central and take full advantage of:}

- Convenient online submission

- Thorough peer review

- No space constraints or color figure charges

- Immediate publication on acceptance

- Inclusion in PubMed, CAS, Scopus and Google Scholar

- Research which is freely available for redistribution

Submit your manuscript at www.biomedcentral.com/submit
C BioMed Central 